\title{
XII. Remarks on a supposed new law of magnetic action
}

\section{Rev. William Ritchie LL.D. F.R.S}

To cite this article: Rev. William Ritchie LL.D. F.R.S (1836) XII. Remarks on a supposed new law of magnetic action, Philosophical Magazine Series 3, 8:43-44, 55-56, DOI: 10.1080/14786443608648797

To link to this article: http://dx.doi.org/10.1080/14786443608648797

册 Published online: 21 Aug 2009.

Submit your article to this journal $₫$

Џ Article views: 3

Q View related articles $\square$ 
Dr. Ritchie on a supposed nere Laro of Magnetic Action. 55

eminent engineers, although they have not thrown the principle into the language of analysis, have nevertheless used it arithmetically; and indeed I have never before heard any doubt expressed about it.

During the Jast autumn I have been engaged in an extensive course of experiments on rail-roads in different parts of the kingdom, with a view to determine with greater precision than has been hitherto attained, the values of the different constant quantities which enter into their theory. The results of all these experiments are in the most perfect accordance with the principle you have called in question. I renain, dear Sir, yours very truly, Dion. Larder.

36, Cambridge Terrace, Edgeware Road, December 14, 1835.

XII. Remarks on a supposed new Law of Magnetic Action. By the Rev. William Ritchie, LI.D., F.h.S, Professor of Natural Philosophy in the Royal Institution of Great Britain and in the University of London.*

$\mathrm{N}$ the last Number of the London and Edinburgh Philosophical Magazinet, Mr. Fox has endeavoured to show that the mutual attraction of two magnets does not follow the law formerly adopted by all philosophers, viz. the law of the inverse square of the distance; but the law of the simple inverse of the distance. This law he deduces from experiments on the attraction of the opposite ends or poles of magnets placed at very small distances from each other. Thus, for example, when the ends of the magnets are at the distance of $\frac{1}{200}$ of an inch, he found the effect to be only one half of what it was when they were in contact; when removed to the distance of $\frac{1}{1000}$ of an inch the effect was one half of one half, or one fourth; when separated by a distance of $\frac{1}{50}$ of an inch, the force was only one half of one fourth, or one eighth, \&c.; which numbers are to each other in the inverse ratio of the distances

I admit the truth of the experiments, but differ from $\mathrm{Mr}$. Fox in the conclusion he has drawn from them. To show that the deduction is unfounded, we must first describe what is meant by the pole of a magnet, and its position with regard to the extremity of the magnet. The pole of a magnet is the centre of parallel forces of all the attractions and repulsions of the elementary magnets of which it is composed. Now the position of this centre will obviously depend on the form of

- Communicated by the Author.

$\uparrow$ Vol. vii. p. 439. 
the magnet, and also on its length. Biot has shown that in a steel wire 24 inches long, and properly magnetized, the pole is an inch and a half from its extremity, and that this distance diminishes with every diminution in the length of the magnet*. The centre of parallel forces or the pole of a magnet is similar to the centre of gravity of a body. In the one case the effect is the same as if all the matter of which the body is composed were concentrated in the centre of gravity, in the other the effect is the same as if the difference between the sum of all the attractive and repulsive forces were concentrated in the pole. Now, in the case of the muiual attraction of bodies, our measurements are always taken between the centres of gravity; in the case of magnetic attractions the distances of the magnets are, in fact, the distances between the poles.

Let the distance of the poles of the magnets when in apparent contact be called2, as in fig. (1.), and then separated by an interval of 1 , as in fig. (2.), and by intervals of 2 . as in

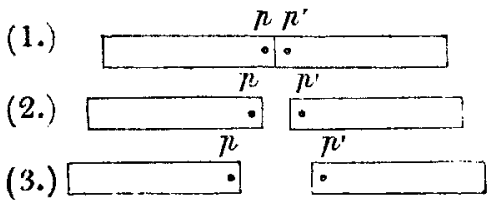
fig. (3.)

Then the distances between the centres of force in these three positions are $2,3,4$. Hence if the law of the inverse squares of the distances, investigated by Coulomb, be the real law of action, the attractive forces will be inversely as $2^{2}, 3^{2}, 4^{2}$, that is, as $\frac{1}{4}, \frac{1}{9}, \frac{1}{16}$; but $\frac{1}{9}$ is nearly the half of one fourth, and $\frac{1}{16}$ nearly the half of $\frac{1}{9}$, as $\mathrm{Mr}$. Fox found by actual experiment. These experiments then, instead of leading to a new law of action, afford a beautiful illustration of that law which universally prevails whenever we have matter acting on matter by attractive or repulsive forces.

XIII. Description of a Thermometer for determining minute Differences of Temperature. By Marshald Hali, M.D., F.R.S.\&. $\dagger$

IN pursuit of the theory of the inverse ratio of the respiration and of the irritability in the animal kingdom, announced in a late volume of the Philosophical Transactions $\ddagger$, I have found it absolutely necessary to determine the minute

* Biot, Traité de Physique, tom. iii. p. 90.

+ Communicated by the Anthor.

In abstract of Dr. Marshall Hall's paper on this subject will be found in Phil. Mag. and Annals, N.S. vol. xi. p. 453.-Eort. 